\title{
Sistem Pakar Penentuan Gaya Belajar Siswa Dengan Metode Forward Chaining Berbasis Web
}

\author{
Laelia Puti Aditasari ${ }^{1}$, Mega Novita ${ }^{2}$, Rahmat Robi Waliyansyah ${ }^{3}$ \\ Program Studi Informatika, Fakultas Teknik dan Informatika, Universitas PGRI Semarang ${ }^{1,2,3}$ \\ aditasarilaelia@gmail.com ${ }^{1}$,novita@upgris.ac.id ${ }^{2}$,rahmat.robi.waliyansyah@upgris.ac.id ${ }^{3}$
}

\section{Article Info}

History :

Dikirim 31 Maret 2020

Direvisi 29 April 2020

Diterima 14 Juli 2020

\section{Kata Kunci :}

Gaya Belajar

Forward Chaining

Expert System

\begin{abstract}
Abstrak
Di Sekolah Dasar Negeri Penambuhan 01 Pati gaya belajar siswa dalam menyelesaikan soal \& menyerap atau mempelajari pelajaran pasti berbeda-beda. Penulis berinisiatif untuk membuat Sistem Pakar Penentuan Gaya Belajar Siswa Berbasis Web dengan Metode Forward Chaining untuk menentukan gaya belajar siswa yang berlainan. Dalam pembangunan software ini memakai database MySQL \& bahasa pemrograman PHP. Pengetesan dilakukan menggunakan uji coba black box dengan hasil pengujian 100\% aplikasi layak digunakan, pengujian White Box dengan hasil perhitungan kompleksitas siklomatis yaitu 2 , sebab jika nilainya kurang dari 10 dikategorikan ke dalam algoritma yang memenuhi kriteria rekayasa software \& tidak kompleks. Berdasarkan pengujian validasi ahli yang dilakukan tiga responden dengan hasil pengujian $76 \%$ maka aplikasi penentuan gaya belajar siswa sudah berfungsi dengan baik. Sedangkan pengujian User Acceptance Test yang dilaksanakan pada lima responden penguji dengan hasil pengujian $89,7 \%$ yang artinya aplikasi layak digunakan oleh pengguna.
\end{abstract}

(C) This work is licensed under a Creative Commons Attribution-ShareAlike 4.0 International License.

\footnotetext{
Koresponden:

Rahmat Robi Waliyansyah

Program Studi Informatika, Fakultas Teknik dan Informatika

Universitas PGRI Semarang

Jl. Sidodadi timur No.24, Kota Semarang, Indonesia, 50232

Email : rahmat.robi.waliyansyah@upgris.ac.id
}

\section{PENDAHULUAN}

Gaya belajar dapat diartikan sebagai kecenderungan siswa dalam menghadapi aturan yang spesifik selama proses belajar sebagai tanggung jawab dalam memperoleh suatu pendekatan belajar yang ideal dengan pedoman dari mata pelajaran atau pedoman belajar di sekolah [1]. Gaya belajar diperoleh dari dalam diri yang mebuat sesorang menjadi senang dan tertarik pada kegiatan belajar. Gaya belajar seseorang dalam menjawab tiap soal \& untuk menerima atau memahami mata pelajaran sudah pasti tidak sama. Di antara siswa yang ada, banyak lebih menyukai guru mereka menyampaikan segalanya bentuk isi pelajarannya di white board. Namun, beberapa siswa yang lain lebih menyukai guru mereka menyampaikannya isi pokok mata pelajaran dengan lisan \& siswa mendengarkan agar dapat memahaminya [2]. Kemudian ada siswa yang lain lebih menyukai membuat kelompok belajar yang kecil guna membahas pertanyaan yang terkait pelajaran tersebut. Namun banyak proses belajar di kelas masih dapat dijalankan dengan opini bahwa tiap-tiap siswa itu memiliki gaya belajar yang serupa. Sehingga siswa yang tidak mempunyai gaya belajar yang 
serupa dengan guru tersebut bisa menjadi terhambat di dalam mempelajari ilmu yang diberikan, sehingga penyampaian materi tidak akan dicapai dan siswa menjadi merasa jenuh [3].

Metode Forward Chaining merupakan cara bagaimana implementasi yang ideal untuk sistem pakar, sistem aturan produksi dan bisnis. Fungsi dari metode Forward Chaining adalah sebagai pengumpul dari fakta-fakta yang sudah ada sehingga dapat diberikan kesimpulan [4]. Beberapa peneelitian terkait dengan Gaya Belajar Siswa \& Metode Forward Chaining yaitu : Perancangan software dengan metode Forward Chaining yang dapat mengidentifikasi gaya belajar siswa. Penelitian ini dilakukan di SDN Sumampir. Expert system ini bisa memberikan soal-soal dengan ciri-ciri gaya belajar yang digunakan, kemudian hasil akhir dari system ini memberikan informasi terkait gaya belajarnya [5]. Expert System dengan Metode Forward Chaining dalam memetakan kelas siswa LBB "abc". Akurasi pada riset ini yaitu $96,67 \%$ \& persentase kesalahan diperoleh 3,33\%. Aplikasi ini diharapkan bisa membantu stackeholder pada saat membuat keputusan sehingga bisa membuat saran untuk orang tua murid dan potensi anaknya bias dioptimalkan supaya dapat berprestasi [6]. Expert System berbasis android dalam menentukan potensi anak dengan menggunakan metode backward chaining. Hasil dari uji coba menampilkan bahwa expert system penentuan potensi anak dengan metode backward chaining bisa meminimalisir pertanyaan-pertanyaan yang wajib dijawab oleh user \& dapat menampilkan informasi potensi anak berdasarkan standar US Office Of Education (USOE) America serta bisa melihat rekapitulasi bakat anak dan indicator yang berdasarkan provinsi atau pulau di Indonesia [7]. Sistem pakar untuk mendeteksi kepribadian dan karakteristik diri menggunakan Forward Chaining. Software ini dibuat dengan bahasa pemrograman berbasis web, tujuannya yaitu supaya bisa memberikan solusi di mana hasil psikotes bisa dilihat langsung setelah user menjawab setiap soal yang ada sebab secara otomatis sistem bisa menganalisis jawaban yang diberikan oleh user [8].

Dari beberapa penelitian terkait, peneliti memilih metode Forward Chaining sebab metode tersebut bisa bekerja ketika trouble berawal dari informasi yang dikumpulkan, selanjutnya mencari kesimpulan apa yang bisa dipakai dari informasi-informasi tersebut [9]. Dengan menggunakan metode tersebut maka diharapkan para siswa lebih tertarik dalam proses belajar dan tidak membosankan. Siswa akan menjadi merasa santai, tidak merasa tegang dan senang pada saat mengikuti pembelajaran. Metode Forward Chaining ini diharapkan bias membantu imajinasi anak lebih baik supaya mudah dipahami, alhasil minat siswa dalam belajar bisa meningkat. Dengan adanya aplikasi ini guru lebih mudah menentukan gaya belajar masing-masing siswa kemudian dikelompokkan berdasarkan gaya belajar siswa agar proses pembelajaran serta pengajaran guru lebih kondusif \& efektif agar tercapai hasil pembelajaran yang lebih baik.

\section{METODE PENELITIAN}

Kerangka berpikir yaitu model konseptual tentang bagaimana teori bisa berkomunikasi dengan banyak faktor yang telah teridentifikasi sebagai permasalahan yang penting. Model pengembangan aplikasi yang dipakai pada penelitian ini yaitu Waterfall. Model tersebut merupakan sebuah model untuk membuat sebuah software yang memiliki sumber daya manusia dalam jumlah yang terbatas \& tidak terlalu besar [10]. Gambar 1 dibawah ini menampilkan kerangka berpikir. 


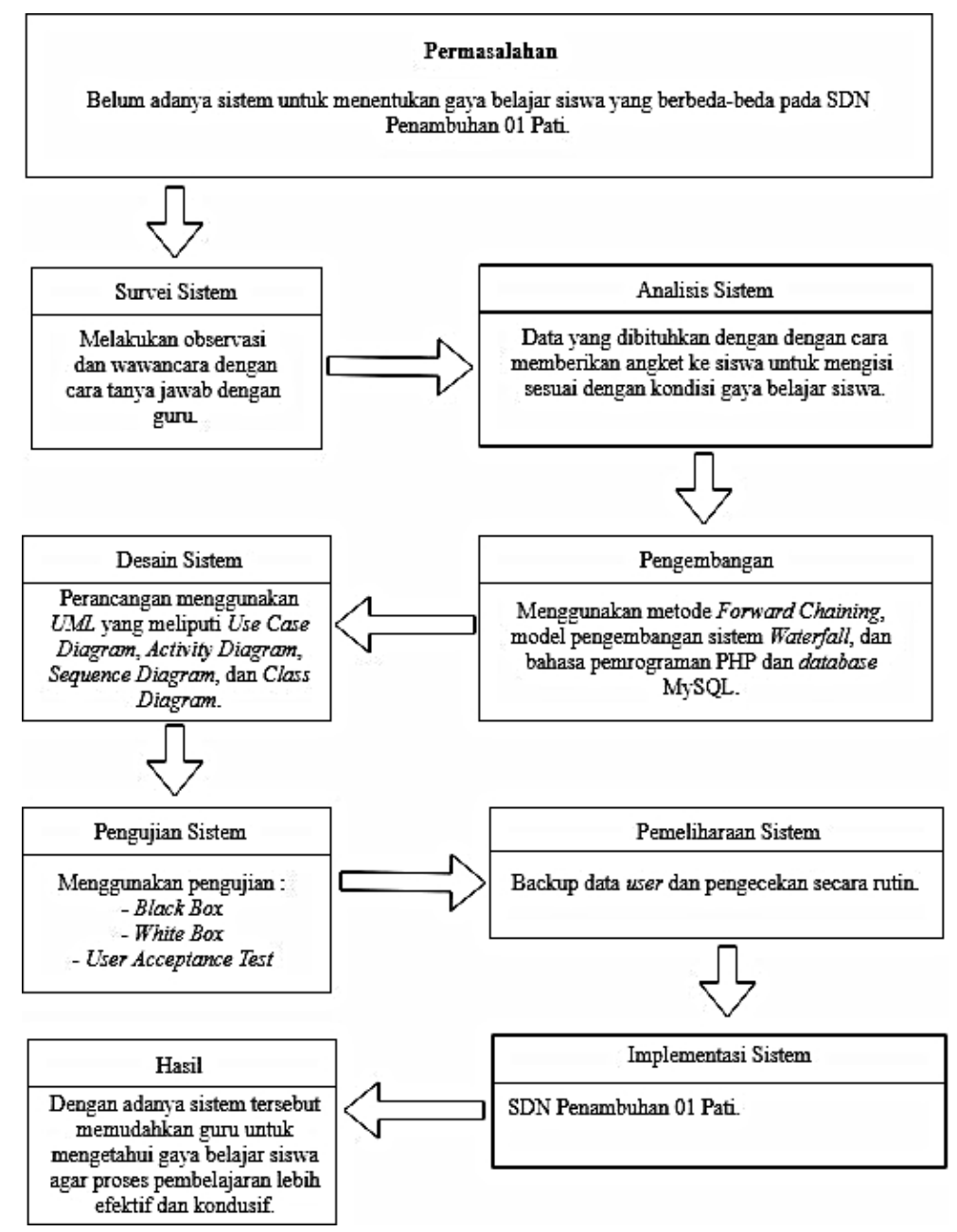

Gambar 1. Kerangka Berpikir.

Menurut Giarattano dan Riley (1994). Metode Forward Chaining baik dipakai sebagai problem solved dalam peramalan \& pengendalian [9]. Forward Chaining tersebut baik sekali apabila menyelesaikan problem dengan informasi awal yang direkam $\&$ ingin mencapai akhir dari penyelesaian, sebab semua proses akan dieksekusi dengan berurutan maju. Proses penalaran Forward Chaining ditampilkan pada gambar 2:

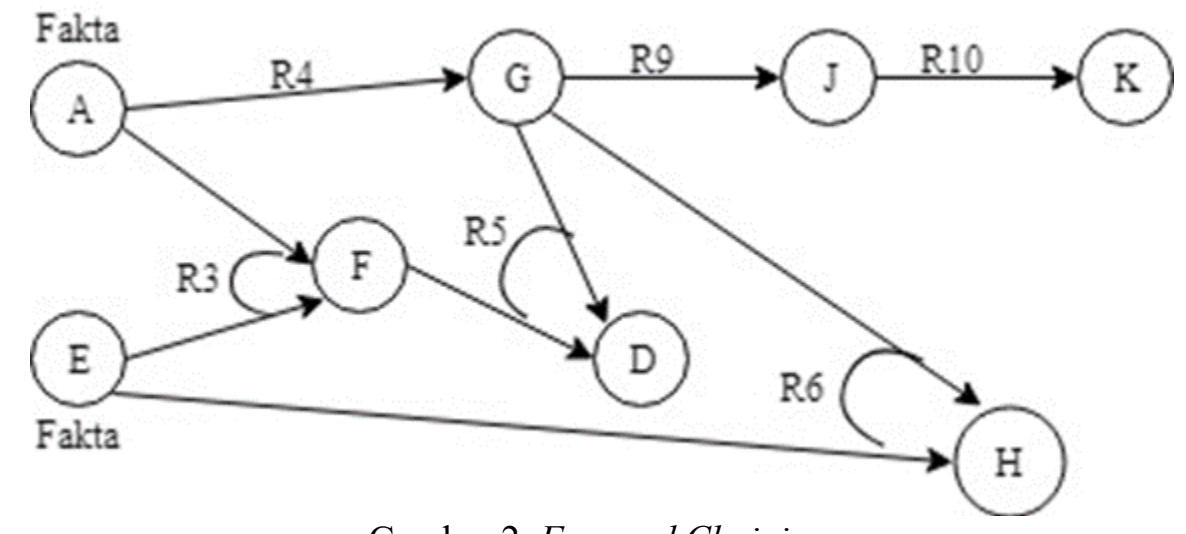

Gambar 2. Forward Chaining. 


\section{HASIL DAN PEMBAHASAN}

1. Implementasi

Hasil dari pembangunan sistem ini bisa dilihat pada gambar 3 dan 4 yang menampilkan halaman login admin \& siswa, gambar 4 menunjukkan dashboard admin serta gambar 5 dan 6 menampilkan tes siswa dan hasilnya.

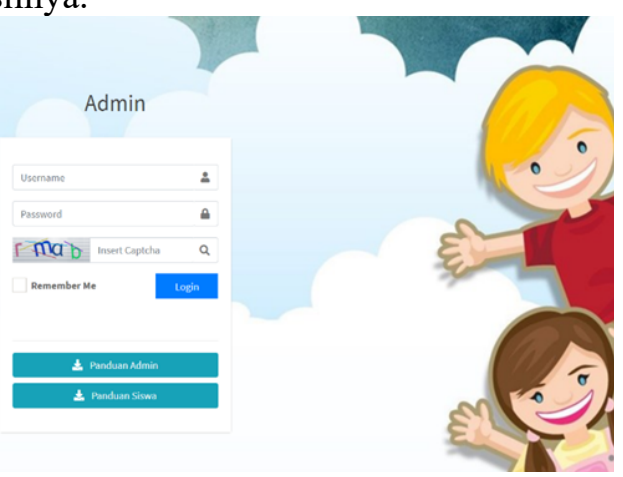

Gambar 3. Tampilan Login Admin.

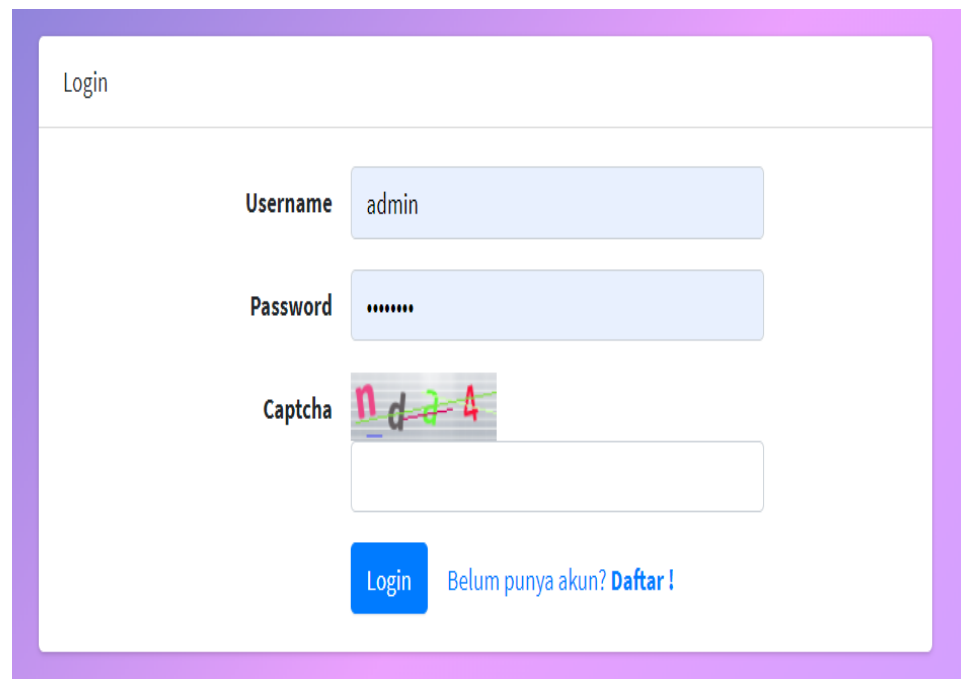

Gambar 4. Tampilan Login Siswa.
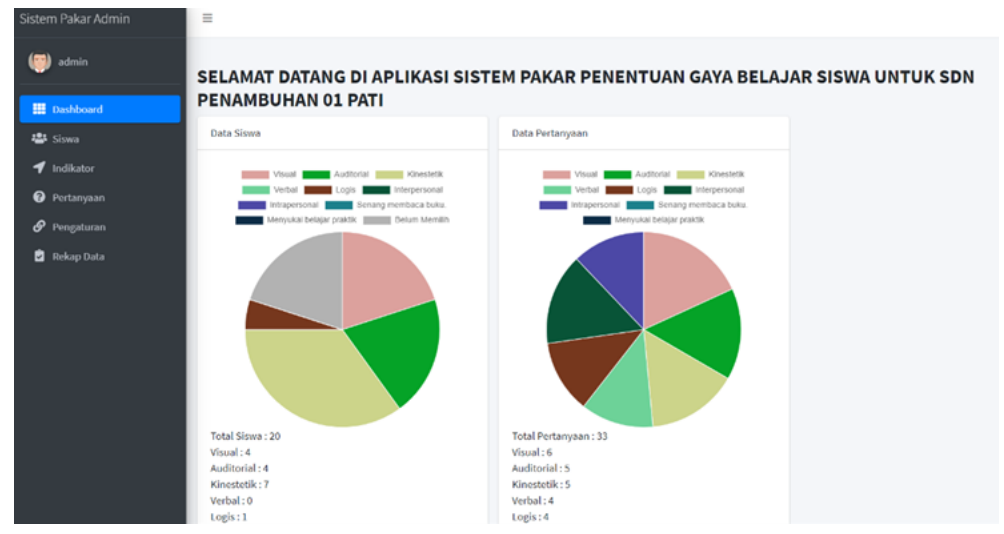

Gambar 5. Tampilan Dashboard Admin. 


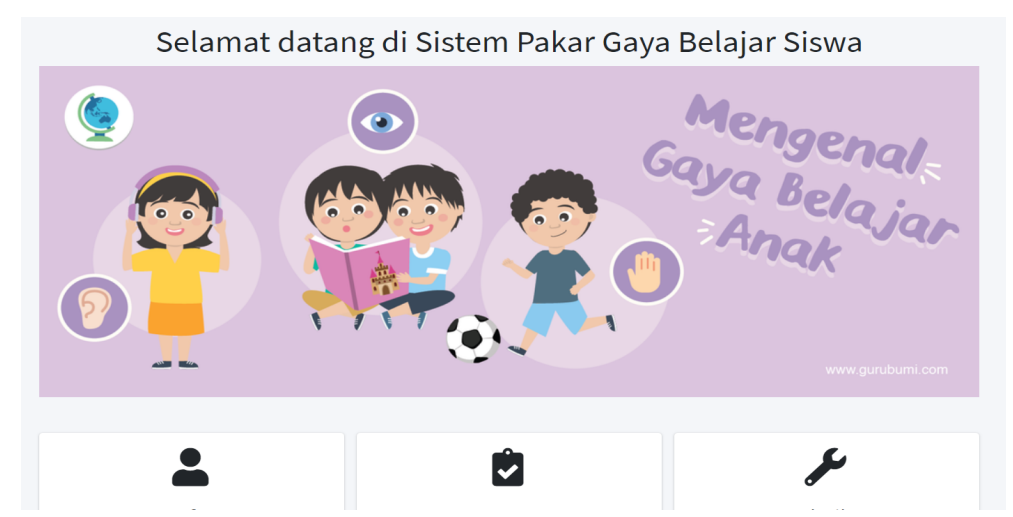

Gambar 6. Tampilan Test.

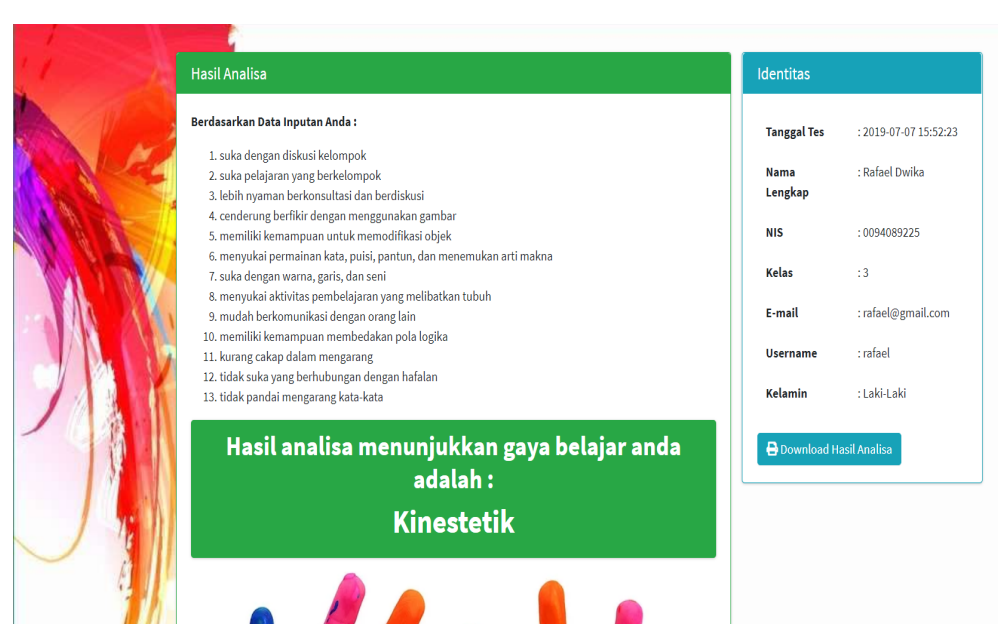

Gambar 7. Tampilan Hasil Test.

2. Pengujian

Pengujian kelayakan sistem dilakukan dengan 4 penelitian yaitu blackbox \& whitebox testing, user acceptance test, dan validasi ahli. Pada pengujian blackbox layak digunakan dengan persentase $100 \%$ [11]. Pada pengujian whitebox hasil perhitungan kompleksitas siklomatis konsultasi data yang dihasilkan adalah 9 termasuk dalam algoritma yang memenuhi kriteria rekayasa perangkat lunak \& tidak kompleks. Pada pengujian user acceptance test memiliki rata-rata $89,7 \%$ maka dinyatakan aplikasi ini layak digunakan oleh pengguna. Pada validasi ahli memiliki rata-rata $76 \%$ maka aplikasi sudah berfungsi dengan baik.

Tabel 1. Uji Coba Black Box.

\begin{tabular}{|c|c|c|c|c|c|}
\hline \multirow[t]{2}{*}{ Nama Pengujian } & \multirow[t]{2}{*}{ Tujuan } & \multirow[t]{2}{*}{ Skenario } & \multirow{2}{*}{$\begin{array}{l}\text { Hasil yang di } \\
\text { harapkan }\end{array}$} & \multicolumn{2}{|c|}{ Pengujian } \\
\hline & & & & Valid & $\begin{array}{l}\text { Tidak } \\
\text { Valid }\end{array}$ \\
\hline $\begin{array}{l}\text { Menampilkan } \\
\text { halaman login. }\end{array}$ & $\begin{array}{l}\text { Admin dapat login dan } \\
\text { masuk ke dalam sistem. }\end{array}$ & $\begin{array}{l}\text { Admin memasukkan alamat } \\
\text { browser } \\
\text { localhost/pkr/public/login. }\end{array}$ & 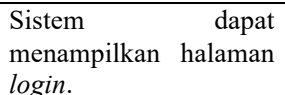 & OK & \\
\hline $\begin{array}{l}\text { Menampilkan } \\
\text { halaman dashboard. }\end{array}$ & $\begin{array}{l}\text { Admin dapat login dan } \\
\text { masuk kedalam sistem. }\end{array}$ & $\begin{array}{l}\text { Admin memasukkan } \\
\text { username dan password. }\end{array}$ & $\begin{array}{l}\text { Sistem dapat berjalan } \\
\text { untuk menampilkan } \\
\text { dashboard r dan } \\
\text { menampilkan pesan } \\
\text { "selamat datang admin } \\
\text { "“ }\end{array}$ & OK & \\
\hline $\begin{array}{l}\text { Menampilkan menu } \\
\text { siswa yang sudah } \\
\text { daftar. }\end{array}$ & $\begin{array}{l}\text { Admin dapat menambah, } \\
\text { mengedit, melihat dan } \\
\text { menghapus data siswa. }\end{array}$ & $\begin{array}{l}\text { Admin memilih tombol } \\
\text { menu siswa. } \\
\text { Sistem menerima request }\end{array}$ & $\begin{array}{l}\text { Sistem dapat berjalan } \\
\text { dengan baik untuk } \\
\text { menampilkan halaman }\end{array}$ & OK & \\
\hline
\end{tabular}

$\overline{\text { Laelia Puti Aditasari, Sistem Pakar Penentuan Gaya Belajar Siswa Berbasis Web Dengan Metode Forward }}$ Chaining 


\begin{tabular}{|c|c|c|c|c|c|}
\hline \multirow[t]{2}{*}{ Nama Pengujian } & \multirow[t]{2}{*}{ Tujuan } & \multirow[t]{2}{*}{ Skenario } & \multirow{2}{*}{$\begin{array}{l}\text { Hasil yang di } \\
\text { harapkan }\end{array}$} & \multicolumn{2}{|c|}{ Pengujian } \\
\hline & & & & Valid & $\begin{array}{l}\text { Tidak } \\
\text { Valid }\end{array}$ \\
\hline $\begin{array}{l}\text { Menampilkan menu } \\
\text { indikator. }\end{array}$ & $\begin{array}{l}\text { Admin bisa menambah, } \\
\text { mengedit, melihat dan } \\
\text { menghapus data indikator. }\end{array}$ & $\begin{array}{l}\text { dan menampilkan data } \\
\text { siswa yang sudah daftar. } \\
\text { Admin memilih tombol } \\
\text { menu indikator. Sistem } \\
\text { menerima request data } \\
\text { yang sudah diinput. }\end{array}$ & $\begin{array}{l}\text { menu siswa. } \\
\text { Sistem dapat berjalan } \\
\text { dengan baik untuk } \\
\text { menampilkan halaman } \\
\text { menu indikator. }\end{array}$ & OK & \\
\hline $\begin{array}{l}\text { Menampilkan menu } \\
\text { pertanyaan. }\end{array}$ & $\begin{array}{l}\text { Admin bisa menambah, } \\
\text { mengedit, melihat dan } \\
\text { menghapus }\end{array}$ & $\begin{array}{l}\text { Admin memilih tombol } \\
\text { menu pertanyaan. }\end{array}$ & $\begin{array}{l}\text { Sistem dapat berjalan } \\
\text { dengan baik untuk } \\
\text { menampilkan halaman }\end{array}$ & OK & \\
\hline $\begin{array}{l}\text { Menampilkan menu } \\
\text { pengaturan }\end{array}$ & $\begin{array}{l}\text { pertanyaan. } \\
\text { Admin bisa menambah } \\
\text { dan meghapus data parent } \\
\text { dan child. }\end{array}$ & $\begin{array}{l}\text { Admin memilih tombol } \\
\text { menu pengaturan. }\end{array}$ & $\begin{array}{l}\text { menu pertanyaan. } \\
\text { Sistem dapat berjalan } \\
\text { dengan baik untuk } \\
\text { menampilkan halaman } \\
\text { menu pengaturan. }\end{array}$ & OK & \\
\hline $\begin{array}{l}\text { Menampilkan menu } \\
\text { rekap data. }\end{array}$ & $\begin{array}{l}\text { Admin bisa menambah, } \\
\text { mengedit, melihat dan } \\
\text { menghapus rekap data. }\end{array}$ & $\begin{array}{l}\text { Admin memilih tombol } \\
\text { menu rekap data. }\end{array}$ & $\begin{array}{l}\text { Sistem dapat berjalan } \\
\text { dengan baik untuk } \\
\text { menampilkan halaman } \\
\text { menu rekap data. }\end{array}$ & OK & \\
\hline $\begin{array}{l}\text { Menampilkan menu } \\
\text { test. }\end{array}$ & $\begin{array}{l}\text { Siswa mengisi pertanyaan } \\
\text { yang sudah disiapkan. }\end{array}$ & $\begin{array}{l}\text { Siswa memilih tombol hasil } \\
\text { test siswa. }\end{array}$ & $\begin{array}{l}\text { Sistem dapat berjalan } \\
\text { dengan baik untuk } \\
\text { menampilkan menu } \\
\text { test. }\end{array}$ & OK & \\
\hline
\end{tabular}

Berdasarkan hasil pengujian pada Tabel 1 tersebut dapat diketahui persentase ketercapaian sebagai berikut:
Tercapai
$=8 / 8 \times 100 \%=100 \%$
Gagal
$=0 / 8 \times 100 \%=0 \%$

Maka dari itu hasil pengujian Black Box yang didapatkan dengan interprestasi 100\% layak digunakan.

Pengujian White box merupakan cara untuk mengetes suatu software dengan cara melihat modul untuk bisa menganalisa \& meneliti code dari aplikasi yang dibuat, apakah ada yang sudah benar atau masih salah. Sekilas bias ditarik kesimpulan pengujian white box adalah clue agar memperoleh aplikasi yang sudah betul 100\%. Berikut adalah hasil pengujian yang dilakukan:

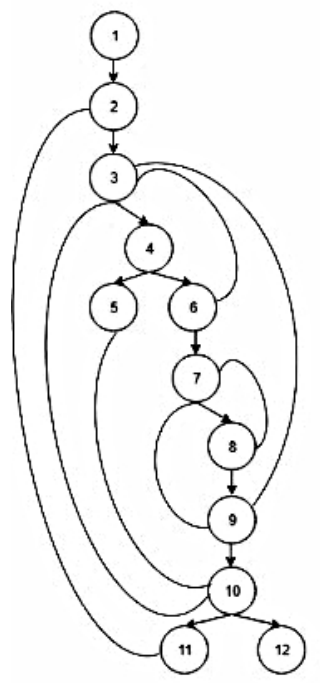

Gambar 7. Basis Path Test.

a. Ambil data siswa

b. Ambil data pertanyaan

c. Loop pertanyaan parent sesuai pengaturan

d. Apakah parent sudah ditanyakan?

Jika ya maka ditanyakan dahulu 
Jika tidak maka loop parent dihentikan

e. Loop parent dihentikan

f. Apakah parent sudah ditanyakan?

Jika ya maka kembali ke loop parent

Jika tidak maka lanjut ke loop child

g. Loop pertanyaan child sesuai pengaturan

h. Apakah child sudah ditanyakan?

Jika ya maka kembali ke loop child

Jika tidak maka simpan pertanyaan

i. Apakah pertanyaan child ketemu?

Jika ya maka ke jawaban keseluruhan

Jika tidak maka kembali ke loop parent

j. Apakah pertanyaan ketemu?

Jika ya maka kembali ke ambil data pertanyaan

Jika tidak maka semua pertanyaan sudah ditanyakan dan lanjut ke hasil test

k. Lanjut ke pertanyaan selanjutnya

1. Hasil test

Tabel 2. Value Tes.

\begin{tabular}{|c|c|c|c|c|}
\hline No & Path & Input & Output & Keterangan \\
\hline 1. & $1,2,3,10,12$ & Jika pertanyaan belum ada & Tidak ada pengaturan & Sukses \\
\hline 2. & $1,2,3,4,5,10,11$ & Jika pertanyaan parent ditanya & Pertanyaan parent ditanya & Sukses \\
\hline 3. & $1,2,3,4,6,7,9,10,12$ & $\begin{array}{l}\text { Jika siswa menjawab semua } \\
\text { pertanyaan }\end{array}$ & $\begin{array}{l}\text { Pertanyaan sudah dijawab } \\
\text { semua }\end{array}$ & Sukses \\
\hline 4. & $\begin{array}{l}1,2,3,4,6,7,8,9,10, \\
11\end{array}$ & Jika pertanyaan child ditanya & Pertanyaan child ditanya & Sukses \\
\hline
\end{tabular}

Berikut penjelasan skor pengujian user acceptance untuk tiap-tiap pertanyaan :

a. Point 1 (sangat tidak setuju)

b. Point 2 (tidak setuju)

c. Point 3 (ragu-ragu)

d. Point 4 (setuju)

e. Point 5 (sangat setuju)

Berikut hasil pertanyaan dari segi kemanfaatan (usefulness) Admin :

a. Apakah aplikasi sistem pakar untuk menentukan gaya belajar ini bermanfaat bagi admin dari segi pelayanan menentukan gaya belajar?

b. Apakah aplikasi sistem sistem pakar untuk menentukan gaya belajar ini bermanfaat bagi admin dari segi kinerja menentukan gaya belajar?

c. Apakah aplikasi sistem sistem pakar untuk menentukan gaya belajar ini bermanfaat bagi admin dari segi efektifitas menentukan gaya belajar?

d. Apakah aplikasi sistem sistem pakar untuk menentukan gaya belajar ini bermanfaat bagi admin dari segi kegunaan dalam proses menentukan gaya belajar?

Tabel 3. User Acceptance dari segi kemanfaatan (usefulness) Admin.

\begin{tabular}{ccccc}
\hline Responden & \multicolumn{5}{c}{ Pertanyaan dan skor } \\
\cline { 2 - 5 } & 1 & 2 & 3 & 4 \\
\hline 1 & 4 & 5 & 4 & 5 \\
Jumlah & 4 & 5 & 4 & 5 \\
\hline Persentase & $80 \%$ & $100 \%$ & $80 \%$ & $100 \%$ \\
\hline Rata-rata Presentasi & \multicolumn{5}{c}{$90 \%$} \\
\hline
\end{tabular}


Berikut hasil pertanyaan dari segi kemanfaatan (usefulness) Guru :

a. Apakah aplikasi sistem pakar untuk menentukan gaya belajar ini bermanfaat bagi siswa dan guru dari segi pelayanan menentukan gaya belajar?

b. Apakah aplikasi sistem pakar untuk menentukan gaya belajar ini bermanfaat bagi siswa dan guru dari segi kinerja menentukan gaya belajar?

c. Apakah aplikasi sistem pakar untuk menentukan gaya belajar ini bermanfaat bagi siswa dan guru dari segi efektifitas menentukan gaya belajar?

d. Apakah aplikasi sistem pakar untuk menentukan gaya belajar ini bermanfaat bagi siswa dan guru dari segi kegunaan dalam proses menentukan gaya belajar?

Tabel 4. User Acceptance dari segi kemanfaatan (usefulness) Guru :

\begin{tabular}{ccccc}
\hline \multirow{2}{*}{ Responden } & \multicolumn{5}{c}{ Pertanyaan dan skor } \\
& 1 & 2 & 3 & 4 \\
\hline 1 & 4 & 4 & 5 & 5 \\
2 & 4 & 5 & 5 & 4 \\
3 & 5 & 4 & 4 & 5 \\
4 & 5 & 5 & 5 & 4 \\
5 & 4 & 5 & 5 & 4 \\
Jumlah & 22 & 23 & 24 & 22 \\
\hline Persentase & $88 \%$ & $92 \%$ & $96 \%$ & $88 \%$ \\
\hline Rata- rata & \multicolumn{5}{c}{$91 \%$} \\
Persentase & \multicolumn{5}{c}{} \\
\hline
\end{tabular}

Berikut daftar pertanyaan dan hasil pada hasil kemudahan penggunaan (Ease of Use)

a. Apakah sistem pakar untuk menentukan gaya belajar siswa ini mudah dipahami?

b. Apakah sistem pakar untuk menentukan gaya belajar siswa ini mudah digunakan?

Tabel 5. Kemudahan Pengguna.

\begin{tabular}{ccc}
\hline \multirow{2}{*}{ Responden } & \multicolumn{2}{c}{ Pertanyaan dan skor } \\
\cline { 2 - 3 } & 1 & 2 \\
\hline 1 & 5 & 4 \\
2 & 5 & 5 \\
3 & 4 & 5 \\
4 & 4 & 4 \\
5 & 5 & 4 \\
Jumlah & 23 & 22 \\
\hline Persentase & $92 \%$ & $88 \%$ \\
\hline Rata - rata & \multicolumn{3}{c}{$90 \%$} \\
\hline
\end{tabular}

Berikut daftar pertanyaan dan hasil pada hasil bentuk (Format)

a. Apakah penyajian outputnya sudah sesuai?

b. Apakah informasinya sudah jelas?

Tabel 6. Kemudahan Bentuk (Format).

\begin{tabular}{ccc}
\hline \multirow{2}{*}{ Responden } & \multicolumn{2}{c}{ Pertanyaan dan skor } \\
\cline { 2 - 3 } & 1 & 2 \\
\hline 1 & 4 & 4 \\
2 & 4 & 4 \\
3 & 4 & 4 \\
4 & 5 & 5 \\
5 & 4 & 5 \\
Jumlah & 21 & 23 \\
\hline Persentase & $84 \%$ & $92 \%$ \\
\hline Rata- Rata & \multicolumn{2}{|c}{$88 \%$} \\
Persentase & \multicolumn{2}{c}{} \\
\hline
\end{tabular}

Untuk mengetahui apakah aplikasi ini layak digunakan yaitu berdasarkan kriteria tersebut:

$100 \% \quad=$ Sangat Layak

$80 \%-99 \%=$ Layak

$70 \%-79 \%=$ Lumayan Layak 
$60 \%-69 \%=$ Tidak Layak

$<59 \% \quad=$ Sangat Tidak Layak

Dari hasil rata-rata Persentase tersebut dapat diketahui persentase ketercapian sebagai berikut:

Total Jumlah Rata - Rata Persentase / Jumlah Aspek = 359\% / $4=89,7 \%$

Dengan Persentase hasil User Accptance 89,7\% maka analisis perancangan sistem pakar penentuan gaya belajar siswa berbasis web dengan metode forward chaining untuk SDN Penambuhan 01 Pati layak digunakan.

Menguji validasian analisis perancangan sistem pakar penentuan gaya belajar siswa berbasis web dengan Metode Forward Chaining Untuk SDN Penambuhan 01 oleh para ahli. Maka point validasi adalah sebagai berikut:

Point 1 = Sangat tidak baik

Point 2 = tidak baik

Point 3 = Cukup baik

Point $4=$ Baik

Point 5 = Sangat baik

Tabel 7. Validasi Ahli.

\begin{tabular}{|c|c|c|c|c|}
\hline \multirow{2}{*}{ Indikator } & \multirow{2}{*}{ Pernyataan } & \multicolumn{3}{|c|}{ Penguji } \\
\hline & & 1 & 2 & 3 \\
\hline Survei Sistem & $\begin{array}{l}\text { Sistem pakar penentuan gaya belajar siswa sudah } \\
\text { sesuai dengan kebutuhan data secara lengkap untuk } \\
\text { menentukan problem-problem atau kebutuhan } \\
\text { yang timbul. }\end{array}$ & 4 & 4 & 3 \\
\hline Analisis Sistem & $\begin{array}{l}\text { Hasil rancangan sistem pakar penentuan gaya } \\
\text { belajar siswa ini sudah sesuai dengan sistem yang } \\
\text { berjalan dan sistem dapat menentukan gaya belajar } \\
\text { siswa. }\end{array}$ & 4 & 4 & 4 \\
\hline Desain Sistem & $\begin{array}{l}\text { Pembangunan sistem pakar penentuan gaya belajar } \\
\text { siswa ini sudah ssesuai dengan hasil perancangan } \\
\text { sistem yang dibangun menggunakan bahasa } \\
\text { pemrograman PHP. }\end{array}$ & 4 & 3 & 4 \\
\hline Implementasi Sistem & $\begin{array}{l}\text { Hasil pengujian black box, white box, dan user } \\
\text { acceptance sudah sesuai dengan sistem yang ada. }\end{array}$ & 4 & 3 & 4 \\
\hline Pemeliharaan Sistem & $\begin{array}{l}\text { Sistem pakar penentuan gaya belajar siswa ini } \\
\text { sudah sesuai dengan prosedur pemeliharaan. }\end{array}$ & 5 & 3 & 3 \\
\hline Jumlah & & 22 & 17 & 18 \\
\hline Persentase $=($ jumlah 1 & nilai $\max ) \times 100 \%$ & $88 \%$ & $68 \%$ & $72 \%$ \\
\hline Rata - rata persentase & lah persentase / jumlah penguji & & $76 \%$ & \\
\hline
\end{tabular}

3. Pembahasan

Untuk menentukan gaya belajar siswa ini dibutuhkan mesin informasi \& pengetahuan agar gaya belajar yang dialami user bisa ditentukan. Basis pengetahuan tersebut terdiri dari faktor-faktor yang dibutuhkan oleh sistem. Terdiri dari jenis gaya belajar, ciri-ciri gaya belajar dan solusi. Input dari sistem ini yaitu data ciri-ciri yang diperoleh dari pakar digunakan oleh sistem untuk menentukan jenis gaya belajar. Pembentukan data ciri-ciri gaya belajar ini dilihat di tabel 8 dan 9.

Tabel 8. Aturan Ciri Gaya Belajar.

\begin{tabular}{ll}
\hline No & \multicolumn{1}{c}{ Aturan } \\
\hline 1 & IF Cenderung berfikir dengan menggunakan gambar $A N D$ Suka dengan warna, garis, dan seni $A N D$ Suka bekerja diruangan \\
& sendirian $A N D$ Tidak mudah terganggu oleh keributan $A N D$ Pasif dalam berdiskusi $A N D$ Tidak pandai mengarang kata-kata \\
& THEN Gaya Belajar Visual \\
2 & IF Suka dengan diskusi kelompok $A N D$ Pandai menirukan nada suara $A N D$ Senang mendengarkan cerita $A N D$ Sering lupa saat \\
& berbicara $A N D$ Kurang cakap dalam mengarang THEN Gaya Belajar Auditori.
\end{tabular}




\begin{tabular}{ll}
\hline No & \multicolumn{1}{c}{ Aturan } \\
\hline 4 & $\begin{array}{l}\text { IF Menyukai permainan kata, puisi, pantun, dan menemukan arti kata } A N D \text { Dapat berkonsentrasi dengan mudah walaupun ada } \\
\text { orang banyak } A N D \text { Suka membaca, berbicara, dan menulis saat belajar } A N D \text { Menafsirkan suatu makna melalui syarat-syarat non } \\
\text { verbal seperti perubahan irama, nada, intonasi dan sering salah mengartikan suatu makna THEN Gaya Belajar Verbal. }\end{array}$ \\
& $\begin{array}{l}\text { IF Tertarik dengan hal-hal yang berhubungan dengan matematika } A N D \text { Memiliki kemampuan membedakan pola logika } A N D \\
\text { Tidak suka yang berhubungan dengan hafalan } A N D \text { Belajar secara autodidak THEN Gaya Belajar Logis }\end{array}$ \\
& IF Mudah berkomunikasi dengan orang lain $A N D$ Lebih nyaman berkonsultasi dan berdiskusi $A N D$ Suka belajar dengan \\
mengutarakan ide/argument $A N D$ Jarang untuk dimintai nasihat teman $A N D$ Konsentrasi terhadap gangguan suara THEN Gaya &
\end{tabular}

Tabel 9. Penjelasan Fakta Dengan Kode.

\begin{tabular}{|c|c|}
\hline Kode & Ciri-ciri \\
\hline $\mathrm{C} 45$ & Suka dengan diskusi kelompok. \\
\hline $\mathrm{C} 46$ & Suka pelajaran yang berkelompok. \\
\hline $\mathrm{C} 47$ & Lebih nyaman berkonsultasi dan berdiskusi. \\
\hline $\mathrm{C} 48$ & Suka belajar mengutarakan ide/argument. \\
\hline C49 & Suka bekerja diruangan sendiri. \\
\hline $\mathrm{C} 50$ & Lebih suka belajar sendiri. \\
\hline $\mathrm{C} 76$ & Belajar secara autodidak. \\
\hline C51 & Tidak mudah terganggu oleh keributan. \\
\hline C75 & Konsentrasi terhadap gangguan suara. \\
\hline C52 & Dapat berkonsentrasi dengan mudah meskipun ada banyak orang. \\
\hline $\mathrm{C} 53$ & Cenderung berfikir dengan menggunakan gambar. \\
\hline C54 & Memiliki kemampuan dalam memodifikasi objek. \\
\hline C55 & Menyukai permainan kata, puisi, pantun, dan menemukan arti kata. \\
\hline C56 & Suka dengan warna, garis, dan seni. \\
\hline C57 & Tertarik dengan hal yang berhubungan dengan matematika. \\
\hline C58 & Menyukai aktivitas pembelajaran yang melibatkan tubuh. \\
\hline C59 & Pandai menirukan suara. \\
\hline C60 & Mudah berkomunikasi dengan orang lain. \\
\hline C61 & Senang mendengarkan cerita. \\
\hline $\mathrm{C} 62$ & Bosan dengan gaya pembelajaran yang hanya duduk diam. \\
\hline C63 & Sering lupa saat berbicara. \\
\hline C64 & Agak sulit berteman dengan orang lain. \\
\hline C65 & Suka membaca, berbicara, dan menulis saat belajar. \\
\hline C66 & Pasif dalam berdiskusi. \\
\hline C67 & Kesulitan dalam menulis. \\
\hline C68 & Memiliki kemampuan membedakan pola logika. \\
\hline C79 & Kurang cakap dalam mengarang. \\
\hline $\mathrm{C} 70$ & $\begin{array}{l}\text { Menafsirkan suatu makna melalui syarat-syarat non verbal seperti perubahan irama, nada, intonasi dan sering salah } \\
\text { mengartikan suatu makna. }\end{array}$ \\
\hline C71 & Sangat sensitif terhadap perasaan orang lain. \\
\hline $\mathrm{C} 72$ & Tidak suka yang berhubungan dengan hafalan. \\
\hline $\mathrm{C} 73$ & Jarang untuk dimintai nasehat teman. \\
\hline $\mathrm{C} 74$ & Tidak pandai mengarang kata-kata. \\
\hline $\mathrm{C} 77$ & Pendengar yang baik. \\
\hline
\end{tabular}

Forward chaining adalah metode inferensi yang digunakan pada sistem tersebut, sebab proses yang dialami dengan memperlihatkan ciri-ciri gaya belajar. Penggunaan Forward chaining untuk pengujian faktor-faktor yang diinputkan oleh user dengan rules yang telah disimpan pada sistem satu per satu sehingga bisa didapatkan sebuah kesimpulan forward chaining. Pada gambar 8 ditampilkan contoh Graf Penelusuran jenis gaya belajar dan Tabel 10 skala gaya belajar 


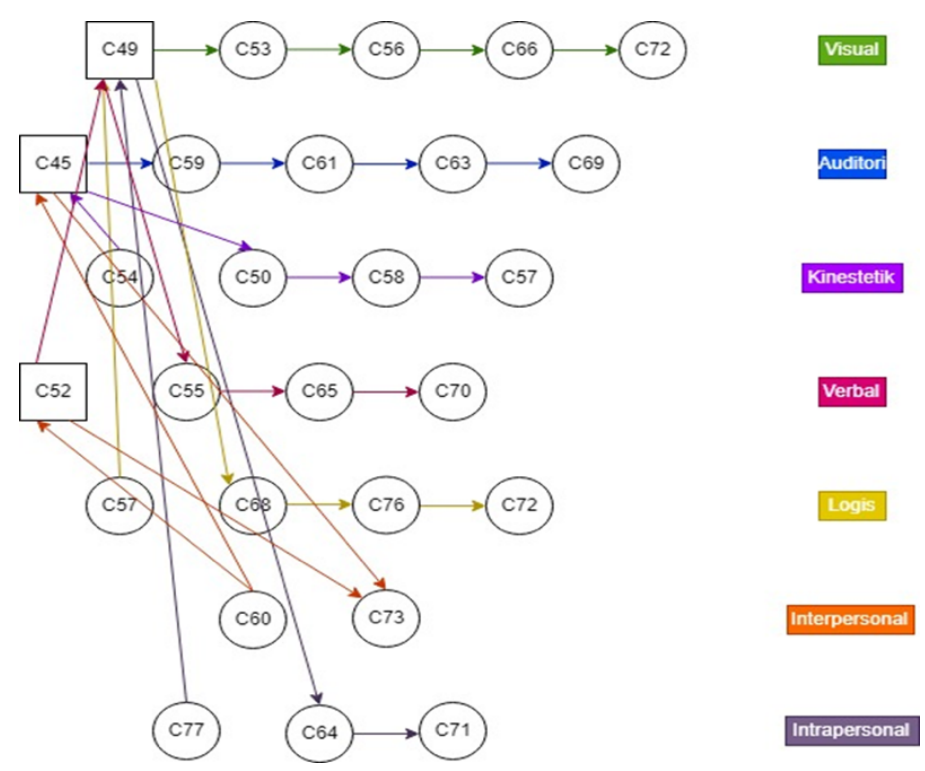

Gambar 8. Diagram Forward Chaining

Tabel 10. Skala Gaya Belajar.

\begin{tabular}{|c|c|c|c|c|}
\hline \multirow{2}{*}{ Variabel } & \multirow{2}{*}{ Indikator } & \multicolumn{2}{|c|}{ Pernyataan } & \multirow{2}{*}{$\begin{array}{c}\text { Jumlah } \\
\text { Item }\end{array}$} \\
\hline & & Positif (+) & Negatif (-) & \\
\hline \multirow{7}{*}{ Gaya Belajar } & Gaya Belajar Visual & $\mathrm{C} 49, \mathrm{C} 51, \mathrm{C} 53, \mathrm{C} 56$ & $\mathrm{C} 66, \mathrm{C} 72$ & 6 \\
\hline & Gaya Belajar Auditori & $\mathrm{C} 45, \mathrm{C} 59, \mathrm{C} 61$ & C63, C69 & 5 \\
\hline & Gaya Belajar Kinestetik & $\mathrm{C} 46, \mathrm{C} 54, \mathrm{C} 58$ & C62 C67 & 5 \\
\hline & Gaya Belajar Verbal & $\mathrm{C} 52, \mathrm{C} 55, \mathrm{C} 65$ & $\mathrm{C} 70$ & 4 \\
\hline & Gaya Belajar Logis & $\mathrm{C} 57, \mathrm{C} 68, \mathrm{C} 76$ & $\mathrm{C} 72$ & 4 \\
\hline & Gaya Belajar Interpersonal & $\mathrm{C} 47, \mathrm{C} 48, \mathrm{C} 60, \mathrm{C} 75$ & $\mathrm{C} 73$ & 5 \\
\hline & Gaya Belajar Intrapersonal & $\mathrm{C} 50, \mathrm{C} 77$ & C64, C71 & 4 \\
\hline \multicolumn{2}{|c|}{ Jumlah Total Item } & & & 33 \\
\hline
\end{tabular}

\section{KESIMPULAN}

Dari penelitian ini bisa diperoleh kesimpulan, yaitu :

a. Aplikasi analisis perancangan sistem pakar penentuan gaya belajar siswa dirancang untuk membantu \& memberikan kemudahan guru dalam mengetahui gaya belajar visual, auditori, kinestetik, verbal, logis, interpersonal, dan intrapersonal dari tiap-tiap siswa supaya proses belajar lebih baik dalam hal pengerjaan soal-soal tes \& pembelajaran yang dilakukan oleh siswa serta pengajaran yang diberikan oleh guru menjadi lebih baik.

b. Berdasarkan pengujian Black Box, aplikasi analisis perancangan sistem pakar penentuan gaya belajar siswa ini layak digunakan dengan persentase $100 \%$ dan dapat berfungsi dengan baik.

c. Berdasarkan pengujian White Box, hasil perhitungan kompleksitas siklomatis konsultasi data yang dihasilkan yaitu 9. Nilai yang dihasilkan kurang dari 10 berarti termasuk ke dalam algoritma yang sudah sesuai dengan kriteria rekayasa perangkat lunak \& tidak kompleks.

d. Berdasarkan pengujian User Acceptance Test yang dilakukan ke lima responden penguji. Aplikasi analisis perancangan sistem pakar penentuan gaya belajar siswa ini memiliki ratarata $89,7 \%$ maka dinyatakan aplikasi ini layak digunakan oleh pengguna.

e. Berdasarkan pengujian Validasi Ahli yang dilakukan ke tiga responden penguji. Aplikasi analisis perancangan sistem pakar penentuan gaya belajar siswa ini memiliki rata-rata $76 \%$ maka software sudah berjalan dengan baik.

f. Aplikasi analisis perancangan sistem pakar penentuan gaya belajar siswa ini menggunakan metode Forward Chaining yang mana hasilnya cukup baik, apabila dikembangkan dengan menggunakan Backward Chaining maka akan mendapatkan hasil yang baru. 


\section{UCAPAN TERIMA KASIH}

Penulis menyampaikan ucapan banyak terima kasih terhadap Kepala Sekolah SDN Penambuhan 01 Kabupaten Pati dan Universitas PGRI Semarang, Indonesia yang sudah memfasilitasi \& membantu dalam penelitian ini.

\section{DAFTAR PUSTAKA}

[1] Y. Wahyuni, "Identifikasi Gaya Belajar (Visual, Auditorial, Kinestetik) Mahasiswa Pendidikan Matematika Universitas Bung Hatta," J. Penelit. dan Pembelajaran Mat., vol. 10, no. 2, pp. 128-132, 2017.

[2] A. Wibowo and N. Atieka, "Identifikasi Gaya Belajar ditinjau dari Kecenderungan Bakat Khusus pada Mahasiswa Program Studi Bimbingan dan Konseling Universitas Muhammadiyah Metro," Indones. J. Educ. Couns., vol. 3, no. 1, pp. 79-84, 2019.

[3] Y. Chania, M. Haviz, and D. Sasmita, "Hubungan Gaya Belajar Dengan Hasil Belajar Siswa Pada Pembelajaran Biologi Kelas X Sman 2 Sungai Tarab Kabupaten Tanah Datar," Sainstek J. Sains dan Teknol., vol. 8, no. 1, p. 77, 2017.

[4] W. Supartini and H. Hindarto, "Sistem Pakar Berbasis Web Dengan Metode Forward Chaining Dalam Mendiagnosa Dini Penyakit Tuberkulosis Di Jawa Timur," Kinetik, vol. 1, no. 3, p. 147, 2016.

[5] M. Ibrohim and N. Purwanty, "Rancang Bangun Aplikasi Identifikasi Gaya Belajar Siswa Dengan Metode Forward Chaining ( Studi Kasus : Sekolah Dasar Negeri Sumampir )," J. ProTekInfo, vol. 4, no. 1, pp. 19-28, 2017.

[6] A. Yaqin and E. Utami, "Sistem Pakar Pemetaan Kelas Siswa LBB 'abc' Menggunakan Metode Forward Chaining," Creat. Inf. Technol. J., vol. 1, no. 1, p. 36, 2015.

[7] F. H. Purwanto and K. Wicaksono, "Sistem Pakar Penentuan Bakat Anak Berbasis Android," in Seminar Nasional Teknologi Informasi dan Multimedia, 2018, pp. 25-30.

[8] D. P. Indah, A. Anton, and U. Radiyah, "Sistem Pakar Deteksi Karakteristik Dan Kepribadian Diri Menggunakan Metode Forward Chaining," J I M P - J. Inform. Merdeka Pasuruan, vol. 3, no. 1, pp. 34-43, 2018.

[9] W. Verina, "Penerapan Metode Forward Chaining untuk Mendeteksi Penyakit THT," J. Tek. Inform. Dan Sist. Inf., vol. 1, no. 2, pp. 123-138, 2015.

[10] G. W. Sasmito, "Penerapan Metode Waterfall Pada Desain Sistem Informasi Geografis Industri Kabupaten Tegal," J. Inform. Pengemb. IT, vol. 2, no. 1, pp. 6-12, 2017.

[11] M. S. Mustaqbal, R. F. Firdaus, and H. Rahmadi, "Pengujian Aplikasi Menggunakan Black Box Testing Boundary Value Analysis (Studi Kasus: Aplikasi Prediksi Kelulusan SNMPTN)," J. Ilm. Teknol. Inf. Terap., vol. I, no. 3, pp. 31-36, 2015. 


\section{BIOGRAFI PENULIS}

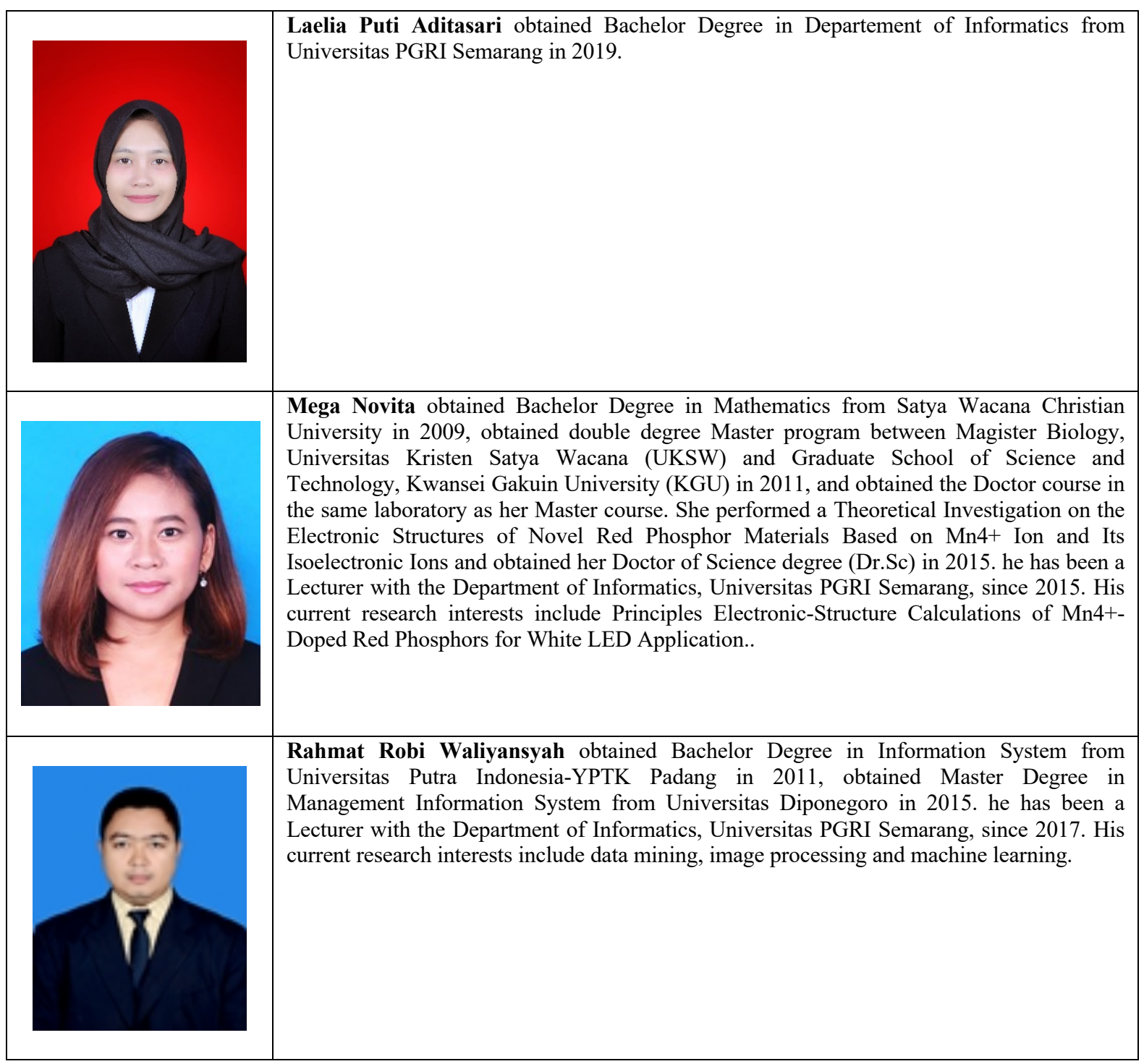

